\title{
15
}

\section{Internet development}

\author{
Fang-Fang Tang
}

\section{A BRIEF HISTORY}

Internet use in mainland China has accelerated in recent years, reaching 68 million users by 30 June 2003, ${ }^{1}$ in sharp contrast to the slowdown in some of the industrialised economies. The latest survey conducted in Taiwan (31 December 2002) shows that the internet penetration rate on the island has reached 38 per cent, or 8.6 million users. A similar survey conducted by the City University of Hong Kong at the end of 2002 indicates that internet users in the Hong Kong number 2.8 million or 45 per cent of the Hong Kong population aged from 6 to 84 , according to the China Internet Network Information Centre (CNNIC) definition, or 2.4 million according to the WIP (World Internet Project) definition or 49 per cent of the population aged from 18 to 74. This chapter focuses on internet development in mainland China, with additional discussions of the situation in Hong Kong and Taiwan when relevant.

Internet development has been dramatic all over the world. Its brief history in China is even more dramatic because of the particular political and social factors.

On 20 September 1987, Professor Qian Tianbai, then in charge of the internet project of China Academic Network (CANET) initiated by the Beijing Municipal Computer Application Research Institute with collaboration with Karlsruhe University in West Germany, sent the first electronic mail, entitled 'Crossing the Great Wall to the World'. This email went through the PAD set up in Beijing by the Italian ATAPAC, routed by the German DATEX.P, at the speed of 300 bytes per second. It was slow and small but historic. Over a year later, in December 1988, Tsinghua University campus network in Beijing adopted the $\mathrm{X} 400$ Protocol, an email software package brought back by Professor Hu Daoyuan from the University of British Columbia 
(UBC), Canada, to connect to the UBC campus through the X.25 network. In the same year, the institute of High Energy Physics in the Academia Sinica in Beijing enacted its DECnet as an extension of the central DECnet in Western Europe through $X .25$, realising international computer networking and email communications with Europe and North America.

In May 1989, the China Research Network (CRN) was connected to the German Research Network (DFN) through the pilot X.25 net built by the then Ministry of Posts and Telecommunications. By that time, the CRN members comprised only a handful of research institutes and universities in Beijing, Shanghai, Chengdu, Shijiazhuang and Nanjing. Nevertheless, the CRN could provide services such as email, file transmission based on File-Transfer Access and Management (FTAM) standard, catalogue based on X.500 standard, and access to the Internet through the DFN. In April 1990, the State Planning Commission organised bidding for a project to build a pilot network of education and research (NCFC) in the Zhongguancun area in Beijing (now China's hi-tech computing centre), with loans from the World Bank and jointly supported by the State Planning Commission, State Science Commission, Academia Sinica, National Natural Science Foundation and State Education Commission. The project aimed to build a high-speed interconnected network connecting Academia Sinica, Peking University and Tsinghua University with a super-computing centre. World Bank loans played a positive role in the development process.

In October 1990, Professor Qian Tianbai, representing China, officially registered China's top domain name as CN in the Defense Data Network Network Information Center (DDN-NIC) of ARPANET (US Department of Defense) which was then in charge of allocation of global internet domain names and internet provider (IP) addresses before the Internet's Information Center (INTERNIC) was established. International email service using $\mathrm{CN}$ domain name started from that time. Since China was not yet formally connected to the internet, Karlsruhe University was commissioned to run the $\mathrm{CN}$ domain name server. At the International Networking (INET) Conference in June 1992 in Kobe, Japan, Qian Hualin, a research fellow at Academia Sinica, met the person in charge of the international network of the US National Science Foundation to discuss the issue of China's official connection to the internet. He was informed, however, that there were political hurdles because many US government organisations were connected to the internet. Nevertheless, that year saw the completion of the National Computing and Networking Facility 
(NCFC) college and institute network project, the CASNET, connecting dozens of research institutes of Academia Sinica and its headquarters, the TUNET of the Tsinghua University campus and the PUNET of the Peking University campus.

On 2 March 1993, the Institute of High Energy Physics, Academia Sinica leased a 64K dedicated line from AT\&T's international satellite channel to connect to the Stanford Linear Accelerator Center (SLAC). But it was only permitted a US Energy network because the US government still excluded 'socialist countries' since there was too much sensitive information about science and technology on the internet. Nevertheless, it was China's first dedicated line with partial access to the internet, so the China State Fund Commission strongly supported this initiative and allocated 300,000 RMB Yuan to enable all leaders of key research projects from various fields to access this line through dialing. Hundreds of scientists in China benefited, and email use within China in general was established. Ten days later, the then Deputy Premier Zhu Rongji put forward a proposal to establish the National Public Economic Information Network-the Golden Bridge Project. Next month the Computer Network Information Center of Academia Sinica brought together some of the network experts in Beijing to determine a framework for the China domain name system, after examining the domain name systems of other countries. In June 1993, NCFC specialists reiterated China's request to be linked to the internet at various possible occasions during the INET'93 conference and won the support of most participants from the international internet community. Qian Hualin discussed China's internet connection at the CCIRN conference and gained majority support.

On 27 August 1993, the then Premier Li Peng approved the use of US $\$ 3$ million of the Premier Reserve Fund to activate the Golden Bridge Project. The following month Deputy Premier Zou Jiahua established the National Joint Conference on Economy Informationalisation. In December, NCFC backbone network construction was completed with high-speed optical fibre wires and routers connecting the three networks of CASNET, TUNET and PUNET. At the beginning of 1994, before the China-America Network Symposium (CANS), US NSF agreed with the request of NCFC to connect to the internet officially. In March 1994, a 64Kbps dedicated line was tested and opened to the public.

In April, the Sino-American Federation of Scientific and Technological Cooperation met in Washington, DC, and Hu Qiheng, the then Vice President of Academia Sinica, reiterated China's request to be linked to the internet. NSF agreed. On 20 April 1994, the NCFC project leased and opened a dedicated $64 \mathrm{~K}$ line through SPRINT Co. of 
the United States to connect China with the internet. This represented official international recognition of China's internet access.

Young people now take internet access for granted but establishing links for China was a complicated process. The Chinese media ranked the country's full access to the internet among the top ten science and technology news items in 1994, and the State Statistics Bulletin ranked it among the major science and technology achievements in the same year.

On 15 May 1994, Academia Sinica's Institute of High Energy Physics set up the first web server with a set of web pages in China. The contents included exhibitions of China's hi-tech development and a window called 'Tour of China', which later extended to include graphics plus information on news, economy, culture, trade and so on, and was renamed as 'Window of China'. This development path is similar to the European integration process, which also began with collaborations in physics research. Soon after, Academia Sinica's Computer Network Information Center completed the installation of China's top domain name server $(\mathrm{CN})$. This was a historic moment.

In June 1994, the General Office of the State Council issued a notice to all provinces and municipalities to start the 'Three Golden Projects'. In September, China Telecom signed an agreement with US Chamber of Commerce to establish international internet links between China and the United States specifying that China Telecom would open two $64 \mathrm{~K}$ dedicated lines provided by the US Sprint Corporation, one line in Beijing and the other in Shanghai. Construction of China's public computer network (CHINANET) started. The following month the State Planning Commission invested in the China Education and Research Network (CERNET), supervised by the State Education Commission. This was a national infrastructure for education and research linking most colleges and middle schools for campus network interconnection and information resources. This was also the first year of the APNG (Asia Pacific Networking Group) Annual Meeting in Tsinghua University, the first international meeting in China on the internet.

In January 1995, China Telecom opened the two 64K lines to the United States provided by the Sprint Corporation and started to offer internet service to the general public through telephone lines, DDN and X.25 network. CERNET then put the journal 'Shen Zhou Scholar' (Chisacm) published by the State Education Commission on the internet. This was the first Chinese language e-journal. Soon after, CERNET opened a 128K dedicated line into the United States. In August 1995, CERNET 
opened the Tsinghua 'ShuiMu'(water-wood) the first internet bulletin board system (BBS) on mainland China.

In January 1996, China Telecom completed the national backbone network of CHINANET and opened nationwide internet access. Soon after, the State Council issued Decree 195 on 'Provisional Regulations of the People's Republic of China on the Management of International Interconnection of Computer Information Network' In September 1996, the China Golden Bridge Information Network (CHINAGBN) opened its $256 \mathrm{~K}$ dedicated line with the United States and announced provision of internet access, mainly for group users through dedicated circuits and for individuals through telephone lines. In November, CERNET opened its $2 \mathrm{M}$ international communication channel. In December, China Public Multimedia Communication Network (169 Net) began full operations, with the opening of its first group of websites, including Guangdong Shilington, Tianfu Online (Sichuan) and Shanghai Online.

The State Council held a National Informationalisation Workshop from 18-21 April 1997 in Shenzhen. This meeting defined the national information system framework, determined the essential factors, missions and guidelines, working principles, objectives and major tasks of such systems, and passed the 'National Informationalisation 95 Planning and Vision Goals of 2000'. It also categorised the internet into the construction agenda of national information infrastructure facilities and proposed the establishment of the National Internet Information Centre and the Internet Exchange Centre. On 20 May 1997, the State Council revised the Provisional Regulations on Internet Management. Ten days later, the Office of Informationalisation Leading Team of the State Council issued the Decree on 'Provisional Regulations of China Internet Domain Name Registration', commissioning Academia Sinica to establish and manage the CNNIC, and the China Education and Research Computer Network Center to contract with the CNNIC for management of the secondary domain names '.edu.cn'.

In November 1997, the CNNIC published its first Statistical Report on Internet Development in China. On 30 December 1997, the Ministry of Public Security issued 'Security Protection Management Regulations of International Interconnection of Computer Information Network', approved by the State Council. In 1997, connection between CHINANET, CSTNET (China Science and Technology Network), CENET (China Economics Network) and CHINAGSN networks was established. Early the following year, the National People's Congress merged several ministries to form the Ministry of Information Industries (MII), which would oversee nation-wide 
manufacturing of electronic and information technology products, telecommunications sector and software industry to advance the knowledge of the national economy and social services.

CERNET opened a satellite network and two satellite systems of CSTNET in January 1991, replacing the IP/X.25 and connecting more than 40 cities in China with high-speed satellite channels. Network speed was significantly improved. In February 1999, they launched the China National Information Security Testing Evaluation Centre (CNISTEC). Then MII cut various charges on internet access service by as much as 50 per cent and cancelled certain charges. China also opened its first ethnic minority website, the Tongyuan Xizhang (Tibet), on the platform of Western Space in Gansu Province in western China. Development of the internet in China was even more rapid after 2000.

\section{RESULTS}

CNNIC started to publish statistical reports on internet development in China in October 1997. This survey adopted international conventions by using a combination of networked computer search methods, user questionnaires and so on. The sampling and statistical methods and results are widely cited in China and internationally. It is one of the most reliable and authoritative surveys in China and has published results every January and July since 1998. A summary of the major findings from this series of reports follows. ${ }^{2}$

First, networked computers and international bandwidth have increased exponentially in mainland China during this period, about 80 and 732 times the October 1997 levels, respectively (Table 15.1). The slight decrease of international bandwidth in late 2002 and early 2003 was mainly due to the reduction of bandwidth by CHINANET and CNCNET (China Netcom Corporation Ltd.) (Table 15.2) although UNINET and CMNET expanded their bandwidth to a different extent. The reason was probably due to market fluctuations reflected in network use, since UNINET and CMNET represented the fast development of mobile telecommunications in China. The decrease of bandwidth gaps among the major service providers, particularly the telecoms, could mean more effective competition in this market.

Business application (com) under ' $\mathrm{CN}$ ' is still the main trend although it was stagnant in 2001-02 due to the burst of the internet bubble in global financial markets (Table 15.3). It should be noted that electronic government is rapidly becoming more common. Investment in e-government in 2002 was about RMB 40 billion and is 
Table 15.1 Growth of networked computers ('000)

\begin{tabular}{lcccc}
\hline & Total & Dedicated line & Dial-up & $\begin{array}{c}\text { International } \\
\text { bandwidth(M) }\end{array}$ \\
October 1997 & 299 & 49 & 250 & 25.4 \\
July 1998 & 542 & 82 & 460 & 84.6 \\
January 1999 & 747 & 117 & 630 & 143.2 \\
July 1999 & 1,460 & 250 & 1,210 & 241.0 \\
January 2000 & 3,500 & 410 & 3,090 & 351.0 \\
July 2000 & 6,500 & 1,010 & 5,490 & $1,234.0$ \\
January 2001 & 8,920 & 1,410 & 7,510 & $2,799.0$ \\
July 2001 & 10,020 & 1,630 & 8,390 & $3,257.0$ \\
January 2002 & 12,540 & 2,340 & 10,200 & $7,597.5$ \\
July 2002 & 16,130 & 3,070 & $12,000+1,060$ & 10576.5 \\
Jan. 2003 & 20,830 & 4,030 & in other ways & \\
July 2003 & & & $14,800+2,000$ & 9380 \\
& 25,720 & 5,150 & in other ways & \\
& & & in other ways & \\
\hline
\end{tabular}

Source: CNNIC Survey

Table 15.2 International bandwidth distribution (million yuan)

\begin{tabular}{lccc}
\hline & July 2002 & January 2003 & July 2003 \\
CSTNET & 55 & 55 & 55 \\
CHINANET & 6452 & 5147 & 10959 \\
CERNET & 257.5 & 259 & 324 \\
UNINET (China Unicom) & 693 & 1093 & 1435 \\
CNCNET (China NetCom) & 2870 & 2469 & 2112 \\
CHINA169 & $n . a$ & & 3465 \\
(broadband by China Netcom) & & $n . a$. & \\
CIETNET & 2 & 2 & 247 \\
(China International Economy and Trade Net) & 247 & 355 & \\
CMNET (China Mobile) & (under construction) & (under construction) \\
CGWNET (China Great Wall Net) & (under construction) & (under construction) \\
CSNET (China Satellite Group Net) & & & \\
\hline
\end{tabular}

Source: CNNIC Survey 
expected to reach RMB 50 billion in 2003. The number of websites has risen from approximately 1,500 in October 1997 to 15,153 in January 2000, 371,600 in January 2003 and 473,900 in July 2003. The geographic distribution of websites and domain names registered under ' $\mathrm{CN}$ ' has been reasonably stable during all surveys since 1997. The North (mainly Beijing), East and South parts of China have accounted for some 85 per cent or even more of the total, while the Northeast, Southwest and Northwest parts of China are still far behind. This pattern reflects disparities in economic development and also in the application of information technology between these regions.

The growth of online users is even more impressive, with rates in double digits in all the years, reaching 68 million in July 2003 (see Table 15.4). In July 2003, it was more than 110 times October 1997 and stands at the position of no. 2 internationally, only just behind the United States. ${ }^{3}$ On the other hand, online users account for merely 5.3 per cent of the population ( 1.3 billion in China), which indicates a huge potential in future growth. Further, it should be noted that dialing-up access maintains the main connection way for the majority of networked computers and also for online users. Broadband is only a recent phenomenon although its growth seems fast. Other economies, from the United States to Europe, and from Japan to South Korea, have put high priority on the development of broadband internet. The case of South Korea is particularly interesting (Tang 2002). The successful penetration of

Table 15.3 Distribution of domain names under ' $\mathrm{CN}$ '

\begin{tabular}{lccccccc}
\hline & COM & EDU & GOV & NET & ORG & others & Total \\
October 1997. & 2131 & 325 & 323 & 370 & 99 & 818 & 4066 \\
July 1998 & 6559 & 414 & 561 & 657 & 229 & 995 & 9415 \\
January 1999 & 13913 & 531 & 982 & 1223 & 409 & 1338 & 18396 \\
July 1999 & 22220 & 615 & 1663 & 2221 & 649 & 1677 & 29045 \\
January 2000 & 38776 & 731 & 2479 & 3753 & 940 & 2016 & 48695 \\
July 2000 & 78878 & 812 & 3665 & 10719 & 1912 & 3748 & 99734 \\
January 2001 & 96221 & 1127 & 4615 & 13291 & 2596 & 4249 & 122099 \\
July 2001 & 99922 & 1239 & 5181 & 15055 & 2864 & 4101 & 128362 \\
January 2002 & 99123 & 1354 & 5864 & 14045 & 2943 & 3990 & 127319 \\
July 2002 & 98835 & 1482 & 6686 & 12248 & 3031 & 3864 & 126146 \\
January 2003 & 133796 & 1629 & 7796 & 20234 & 9587 & 6502 & 179544 \\
July 203 & 341753 & n.a & 7876 & 60408 & 26292 & 35196 & 473900 \\
\hline
\end{tabular}

Source: CNNIC Survey 
broadband use has dramatically changed the way of life and business there. China should pay more attention in this strategically important area. Another worth mentioning is the growth of internet access from equipment other than computer, including mobile devices and home appliances, with users increasing from 200,000 in January 2000 to 1.53 million in January 2003 and to 1.8 million in July 2003. These figures represent a 9 times increase within three and a half years.

Clearly, the pattern of demographic distribution of online users has shifted from a mainly male activity to a more even one (Table 15.5). Male online users still count as 20 per cent more than female ones, but female users have been steadily increasing and have stabilised at about 40 per cent. The disparity has decreased from $7: 1$ in October 1997, to about 3:2 in 2003. Male users number 40.87 million in July 2003, a 16.6 per cent increase from the previous six months and close to 75 times the number in October 1997. Female users number about 27.13 million, a smaller increase of 12.8 per cent but still 358 times the number in October 1997. Nevertheless, male users account for 6.2 per cent of the male population in China and female users only 4.4 per cent of the female population, indicating a much lower Internet penetration rate in females than males in China.

Married people seem to have less time for such a novel hobby, reflected in the stable gap of 20 per cent fewer than unmarried users, although this gap may be narrowing. Clearly usage is linked to the fact that the internet appeals to people

Table 15.4 Growth of online users ('000)

\begin{tabular}{lrcccl}
\hline & Total & Dedicated line & Dial-up & Both ways & \\
October 1997 & 620 & 155 & 465 & n.a. & \\
July 1998 & 1,175 & 325 & 850 & n.a. & \\
January 1999 & 2,100 & 400 & 1,490 & 210 & \\
July 1999 & 4,000 & 760 & 2,560 & 680 & \\
January 2000 & 8,900 & 1,090 & 6,660 & 1,150 & \\
July 2000 & 16,900 & 2,580 & 11,760 & 2,560 & \\
January 2001 & 22,500 & 3,640 & 15,430 & 3,430 & \\
July 2001 & 26,500 & 4,540 & 17,930 & 4,030 & \\
January 2002 & 33,700 & 6,720 & 21,330 & 5,650 & \\
& & & & $1 S D N$ & Broadband \\
July 2002 & 45,800 & 16,060 & 33,420 & 3,150 & 2,000 \\
Jan. 2003 & 59,100 & 20,230 & 48,000 & 4,320 & 6,600 \\
July 2003 & 68,000 & 23,420 & 45,010 & 4,900 & 9,800 \\
\hline
\end{tabular}

Source: CNNIC Survey 
under 35. Married internet users reached 27.4 million by July 2003, or 3.4 per cent of the married population, while there were 40.6 million unmarried users, or 8.6 per cent of the unmarried population. Age seems to be the most important factor determining internet use so far, with the 18-24 year olds being most active, making up 40 per cent of all internet users. The proportion of 25-30 year olds has decreased sharply in the past three years, from 30.8 per cent in January 2000 to 17 per cent in January 2003, while users under 18 have risen rapidly, from 2.4 per cent to 17.6 per cent during the same period. This change has mainly to do with the recent trend of middle school students going online. The proportion of internet users over 35 has been fluctuating by about 2 per cent though generally increasing steadily, numbering 11.08 million in July 2003. The overall pattern seems to indicate that online activities are still more for information and fun than for business.

Table 15.6 summarises the educational level of online users from July 1998 , when this aspect was first surveyed. Obviously, the high school, professional school and three-year college level again account for the majority in recent years, although university-educated people were the main pioneers to use the internet. More specifically, by January 2003, high school and professional school education levels accounted for 30.9 per cent while three year college (Da Zhuan) level accounted for 27.1 per cent. The growth at undergraduate education level or above stood at 6.3 per cent or 1.14 million during the same period. The increasing supply and diversity of online content and lower costs of access services have surely contributed to this change.

Table 15.5 Demographics of online users (per cent)

\begin{tabular}{lcccccc}
\hline & Male & Female & Below 35 & Above 35 & Married & Unmarried \\
October 1997 & 87.7 & 12.3 & 84.1 & 15.9 & n.a. & n.a. \\
July 1998 & 92.8 & 7.2 & 91.1 & 8.9 & n.a. & n.a. \\
January 1999 & 86.0 & 14.0 & 89.8 & 10.2 & 36 & 64 \\
July 1999 & 85.0 & 15.0 & 88.9 & 11.1 & 37 & 63 \\
January 2000 & 79.0 & 21.0 & 88.2 & 11.8 & 36 & 64 \\
July 2000 & 74.7 & 25.3 & 87.6 & 12.4 & 33.4 & 66.5 \\
January 2001 & 69.6 & 30.4 & 83.8 & 16.2 & 37.0 & 62.9 \\
July 2001 & 61.3 & 38.7 & 79.8 & 20.2 & 41.5 & 58.5 \\
January 2002 & 69.0 & 40.0 & 79.9 & 20.1 & 43.1 & 56.9 \\
July 2002 & 60.9 & 39.1 & 82.0 & 18.0 & 41.1 & 58.9 \\
January 2003 & 59.3 & 40.7 & 82.1 & 17.9 & 42.2 & 57.8 \\
July 2003 & 60.1 & 39.9 & 83.7 & 16.3 & 40.3 & 59.7 \\
\hline
\end{tabular}

Source: CNNIC Survey 
Another useful category would be according to occupations or industries. Unfortunately, CNNIC surveys used different industry names or occupation titles at various stages so it is not feasible to summarise them in tables as above. In the latest surveys, January and July 2003, one can see that students account for 28 and 30.1 per cent of online users, more than the technical and professional people at 15.7 and 15.9 per cent. The third ranked are clerks, assistants, commerce and service people at 10.3 and 9.1 per cent, while the agriculture, forestry, cattle-raising and fishing personnel and the military personnel make up only 1, 0.9 and 0.8 per cent respectively of online users. Students are generally more open to novelty and the significant improvement in campus network infrastructure has certainly helped this trend. By January and July 2003, student online users account for 7.4 and 9 per cent of the total student population (including primary to postgraduate students), a 2 per cent increase during six months if one takes into account the vast base of student population in the enormous size of China.

By industry categorisation, personnel from public management and social organisations account for 12.5 per cent among online users, followed by wholesale and retailing personnel (11.8 per cent), manufacturing personnel (11.1 per cent), education and scientific researchers (10.6 per cent), IT personnel (10.3 per cent), financial industry personnel (6.1 per cent), warehousing and transportation workers (4.7 per cent), health, social security and welfare personnel ( 3 per cent) and so on.

Table 15.6 Education level of online users (per cent)

\begin{tabular}{lcccc}
\hline & $\begin{array}{c}\text { Below } \\
\text { high school }\end{array}$ & $\begin{array}{c}\text { College/ } \\
\text { University }\end{array}$ & Undergraduate & Postgraduate \\
July 1998 & 6.9 & 34.2 & 49.6 & 9.3 \\
July 1999 & 2.0 & 39.0 & 48.0 & 11.0 \\
January 2000 & 3.0 & 45.0 & 45.0 & 7.0 \\
July 2000 & 2.5 & 45.6 & 45.9 & 5.9 \\
January 2001 & 6.4 & 52.4 & 38.8 & 2.3 \\
July 2001 & 8.7 & 55.5 & 33.6 & 2.2 \\
January 2002 & 10.2 & 56.9 & 30.4 & 2.5 \\
July 2002 & 11.5 & 56.8 & 29.2 & 2.5 \\
January 2003 & 12.9 & 56.7 & 27.6 & 2.8 \\
July 2003 & 13.9 & 58 & 25.5 & 2.6 \\
\hline
\end{tabular}

Source: CNNIC Survey 
Internet use growth is highest among the health, social security and welfare personnel (83.2 per cent or 0.99 million during 6 months) followed by education personnel (39.8 per cent or 1.67 million) and manufacturing personnel (38.3 per cent during six months). Online user population becomes more and more diverse by occupations or industries, a healthy trend for Internet development in China. The fast growth of online users in manufacturing is interesting, since this sector is increasingly important in the Chinese economy, which is dominated by manufacturing. Increasing familiarity with internet use and e-commerce will enhance the competitiveness and productivity of its workforce and the whole sector.

Beijing, Shanghai and Guangzhou areas clearly dominated Internet use in the early years and still are the most important parts (Table 15.7). But other regions are catching up fast, especially the Northeast and Southwest regions. It would be interesting to make a comparison of users in the East and Northwest, the two ends of the spectrum. According to the CNNIC survey in January 2003, male Internet users account for 58 per cent in the East and female 38 per cent, but 67.5 per cent versus 32.5 per cent in the Northwest -51.9 per cent are unmarried users in the East and 45.3 per cent in the Northwest. The patterns are qualitatively different with sex ratio and marriage status reversed in these two regions. On the other hand, age distribution does not seem to differ between these two regions. Internet users at different age intervals in the East and Northwest were 19.5 per cent versus 19.6 per

Table 15.7 Geographic distribution of online users

\begin{tabular}{lcccccc}
\hline & North & Northeast & East & South & Southwest & Northwest \\
October 1997 & 41.0 & 5.2 & 27.1 & 29.5 & 4.3 & 1.9 \\
July 1998 & 31.6 & 9.6 & 29.3 & 22.6 & 4.2 & 2.7 \\
January 1999 & 28.7 & 6.7 & 24.0 & 30.5 & 5.9 & 4.0 \\
July 1999 & 26.7 & 6.6 & 32.0 & 21.2 & 7.9 & 4.7 \\
January 2000 & 28.0 & 7.4 & 31.6 & 23.6 & 6.0 & 3.2 \\
July 2000 & 25.1 & 6.4 & 35.0 & 22.9 & 6.2 & 4.3 \\
January 2001 & 19.9 & 9.5 & 34.4 & 21.8 & 9.3 & 4.9 \\
January 2002 & 17.7 & 8.4 & 36.0 & 24.3 & 9.0 & 4.6 \\
July 2002 &.. &.. &.. &.. &.. &.. \\
January 2003 & 21.9 & 11.0 & 26.4 & 25.0 & 10.3 & 5.4 \\
July 2003 &.. &.. &.. &.. &.. &.. \\
\hline
\end{tabular}

Note: CNNIC survey began to report by provinces. The author computed according to the traditional regional names (South includes South China and Middle China here).

Source: CNNIC Survey 
Table 15.8 Methods of financing online access

\begin{tabular}{lccc}
\hline & Public & Private & Both ways \\
July 1998 & 35.0 & 44.0 & 21.0 \\
January 1999 & 26.0 & 45.0 & 29.0 \\
July 1999 & 28.0 & 46.0 & 26.0 \\
January 2000 & 21.0 & 59.0 & 20.0 \\
July 2000 & 17.5 & 56.3 & 26.1 \\
January 2001 & 14.1 & 63.3 & 22.4 \\
July 2001 & 12.6 & 70.4 & 17.9 \\
January 2002 & 10.7 & 73.7 & 15.6 \\
July 2002 & 10.1 & 77.1 & 12.8 \\
January 2003 & n.a. & n.a. & n.a. \\
July 2003 & n.a. & n.a. & n.a. \\
\hline
\end{tabular}

Source: CNNIC Survey

cent for below 18, 31.3 per cent versus 23.4 per cent for 18-24, 18.9 versus 18.1 per cent for $25-30,10.8$ versus 17.5 for $31-35,8.2$ per cent versus 11.9 for $36-40,6.9$ per cent versus 6.5 per cent for $41-50,3.5$ per cent versus 1,8 per cent for $51-60$, and 1 per cent versus 1.2 per cent for above 60 . Internet users in the East were younger, 69.7 per cent below 31 while it is 61.1 per cent in the Northwest, not a qualitatively significant difference.

The distribution of educational levels among online users and online timing each day are also similar in these two regions. The frequency of internet use, however, is much higher in the East (11.3 hours and 3.6 days per week on average) than in the Northwest ( 8.4 hours and 3 days per week on the average) and consistently with this average, Eastern users spent more for internet connection than their non-Western counterparts. This pattern is also consistent with the economic development level in these two regions.

The proportion of non-users in the Northwest who wished to go online within a year was higher than in the East. Easterners went online more for information and for fun, while their Northwest counterparts more for education and making friends. The geographic remoteness of the Northwest is probably the contributing factor.

Ways of financing online access have changed dramatically, as reflected in Table 15.8. People have mainly spent their own money for internet access in recent years, and the CNNIC survey has stopped even collecting such data since 2003. It is not surprising, because internet access infrastructure becomes increasingly better and 
cheaper. When we consider that recently, private cars in China exceeded 10 million, it is clear that increasing numbers of people will also finance internet access.

In recent years, the CNNIC surveys started to collect information on the income distribution of internet users, an important improvement. See Table 15.9 for the years 2002 to 2003. Obviously, low income or even no income groups are the main users, thus online retailing in China still has a long to go, except for a few items such as books or online game services. In addition, the average spending on internet access is also rather low, mostly below 100 yuan per month, thus even ISPs must seriously think about their business models for sustainability facing such types of users (students and other young people without regular income). Fortunately, the growth rate of relatively high-income users (above 2000 yuan per month) seems higher than the low-income groups recently-16.6 per cent (from 9.2 per cent, an increase of 10.7 million from January to July 2003), versus 14.8 per cent (from 49.9 million to 57.3 million)-indicating a medium to long run market.

\section{ONLINE ACTIVITIES AND BEHAVIOUR}

Online activities and behaviour of Chinese internet users has evolved significantly, as in most other regions in the world. In the survey of October 1997, there were 10.3 per cent users who went online less than an hour per week, 43.3 per cent between one to five hours, 26.3 per cent five to 10 hours and 20.1 per cent above 10 hours. The distribution changed to 7.1 per cent, 25.3 per cent, 26.7 per cent and 40.9 per cent, respectively, in the survey of July 1998, and 4 per cent, 31 per cent, 29 per cent, and 36 per cent in January 1999. Heavy users increased sharply from about 20 per cent to over 40 per cent in a mere nine months, while the user population was exponentially rising. In the multiple choices of October 1997 survey, 80.4 per cent users wanted science and technology information, 42 per cent looking for social news, 39.6 per cent for commercial information, 32.8 per cent for financial information, and 24.8 per cent for leisure information. Clearly, most users were looking for science and technology information, probably due to the fact that 54.7 per cent users that year were professionals in research, education and IT industry and students, while the proportion of consumption-type users was relatively small. The situation changed dramatically nine months later, with 63.3 per cent users looking for leisure, entertainment and sports information, 67.2 per cent for science and technology, 45.1 per cent for economical and political news, 43.7 per cent for commercial information, 26.1 per cent for financial and securities information, and, interestingly, 
15.2 per cent interested in advertisements. This must be a good time for web portals with an advertisement-based business model.

Common complaints of users were the slow speed online (49.1 per cent in 1997 and 88.9 per cent in 1998), high connection charges (36.2 per cent in 1997 and 61.2 per cent in 1998), and too little information in Chinese language (7.3 per cent in 1997 and 45.5 per cent in 1998). In addition, users began to examine the service quality of ISPs as reflected in the 1998 survey, with 38.4 per cent users regarding the service providers as very good (patient with customers about problem solving and training), 55 per cent feeling so-so (nice at the beginning when attracting users but impatient later) and 6.6 per cent finding the ISPs very bad (no attempt at improving service quality).

Table 15.9 Monthly income distribution of online users (RMB, per cent)

January 2002

$\begin{array}{cccccc}\text { Below 500 } & 501-1,000 & 1,001-1,500 & 1,501-2,000 & 2,001-2,500 & 2,501-3,000 \\ 23.6 & 25.3 & 16.5 & 8.8 & 4.4 & 3.4 \\ 3,001-4,000 & 4,001-5,000 & 5,001-6,000 & 6,001-10,000 & \text { Above } 10,000 & \text { No income } \\ 2.3 & 1.1 & 0.8 & 0.7 & 0.8 & 12.3\end{array}$

July 2002

$\begin{array}{cccccc}\text { Below } 500 & 501-1,000 & 1,001-1,500 & 1,501-2,000 & 2,001-2,500 & 2,501-3,000 \\ 24.8 & 24.1 & 16.5 & 8.2 & 4.6 & 2.6 \\ 3,001-4,000 & 4,001-5,000 & 5,001-6,000 & 6,001-10,000 & \text { Above } 10,000 & \text { No income } \\ 2.7 & 1.3 & 0.7 & 0.6 & 0.9 & 13.0\end{array}$

January 2003

$\begin{array}{cccccc}\text { Below } 500 & 501-1,000 & 1,001-1,500 & 1,501-2,000 & 2,001-2,500 & 2,501-3,000 \\ 23.5 & 20.9 & 15.4 & 8.2 & 5.1 & 3.8 \\ 3,001-4,000 & 4,001-5,000 & 5,001-6,000 & 6,001-10,000 & \text { Above } 10,000 & \text { No income } \\ 3.1 & 1.3 & 0.7 & 0.7 & 0.8 & 16.5\end{array}$

July 2003

$\begin{array}{cccccc}\text { Below } 500 & 501-1,000 & 1,001-1,500 & 1,501-2,000 & 2,001-2,500 & 2,501-3,000 \\ 20.8 & 18.3 & 15.9 & 9.8 & 4.6 & 3.7 \\ 3,001-4,000 & 4,001-5,000 & 5,001-6,000 & 6,001-10,000 & \text { Above } 10,000 & \text { No income } \\ 2.4 & 2.0 & 0.7 & 1.0 & 1.1 & 19.5\end{array}$

Source: CNNIC Survey 
Since January 1999, surveys have collected information about where people go online (Table 15.10). The clear trend is that people are going online mainly in homes. Schools and Internet cafes have become important places for online access in recent years. This pattern corresponds to the increasing penetration of personal computers into Chinese homes, significant improvement in connection infrastructure both in schools and residential areas and a sharp reduction in connection charges. The broadband power and popularity in Internet cafes have been particularly attractive to young users.

The time people spent online exhibited an interesting pattern, dropping from a high 17 hours per week on average in early 2000 to 8.3 hours in mid 2002, but increasing sharply to 13 hours by July 2003 (Figure 15.1). The latest rise is attributed to the impact of SARS.

Survey data on the usual time people go online is shown in Table 15.11 in hour blocks (24 hour clock).

Figures $15.2 a-15.2 b$ show the survey results in January and July 2003, from which one can see that the curve fluctuates a good deal but the pattern has been quite similar from the known surveys in the past years. Fewest people go online between midnight to $7 \mathrm{am}$, and more activities start from $8 \mathrm{am}$. Predictably, the most active period is in the evening, with about 30-40 per cent of users going online during this time.

The hardware used to go online is constantly changing, and notebook computers are increasing rapidly (see Table 15.12). Even novel hardware such as mobile devices and info home appliances are becoming more acceptable to internet users (see Figure 15.3).

The main reasons users go online have also been surveyed (see Table 15.13). Clearly, the dominant purpose is to obtain information, followed by leisure and entertainment, then making friends. The internet has provided another channel for the traditionally conservative Chinese communities for more openness in personal lifestyles, although phenomena like one-night stands resulting from chat rooms are judged immoral by older generations. The fact that needs to be faced and researched is the profound changes accompanying the fast development in the economy and the widespread use of the internet, especially among the younger generation. The temporary setback in the stock trading online had much to do with the problems in the stock markets in China these years, rather than problems associated with the internet. 
Figure 15.1 Average hours online per week, 2000-03

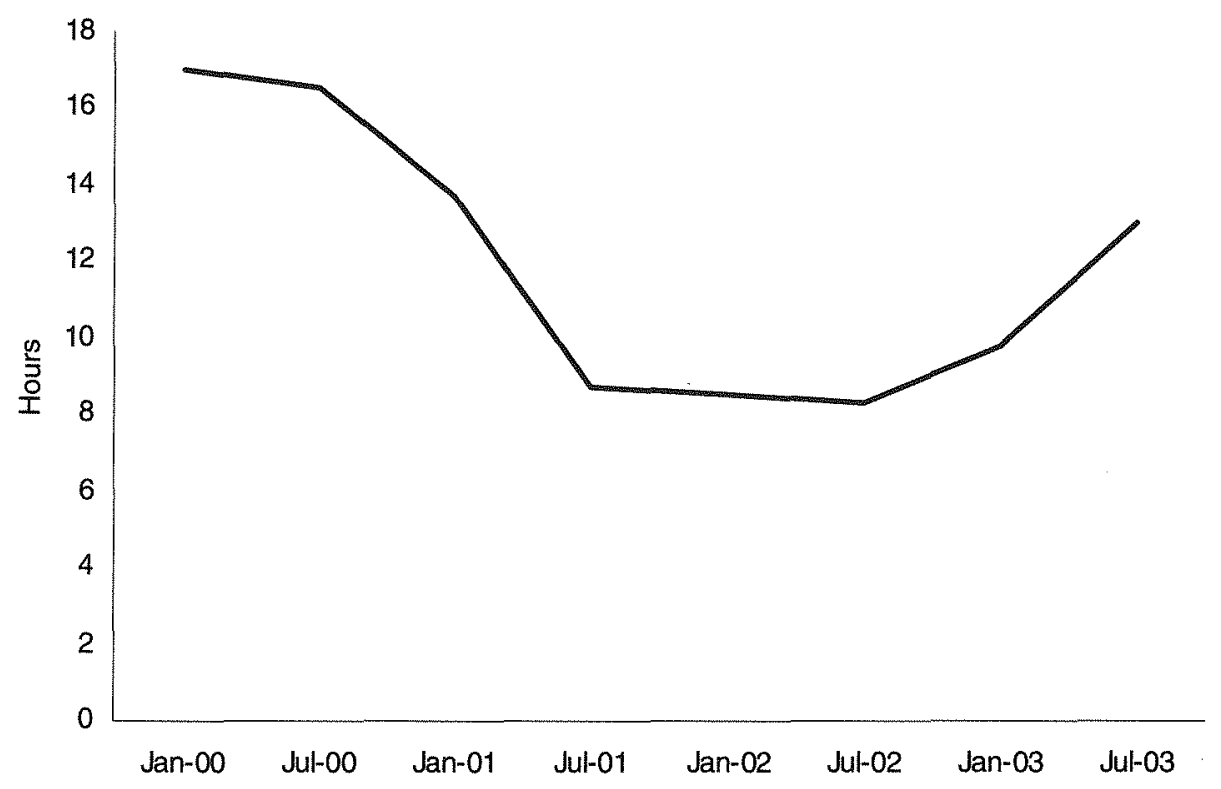

Table 15.10 Main location of going online (per cent)

\begin{tabular}{lccccccc}
\hline Year & Home & $\begin{array}{c}\text { Work } \\
\text { units }\end{array}$ & Schools & $\begin{array}{c}\text { Internet } \\
\text { cafes }\end{array}$ & Other & $\begin{array}{c}\text { Public } \\
\text { library }\end{array}$ & Mobile \\
January 1999 & 44.0 & 50.0 & n.a. & 3.0 & 3.0 &.. &.. \\
July 1999 & 44.0 & 47.0 & n.a. & 4.0 & 5.0 &.. &.. \\
January 2000 & 50.0 & 37.0 & n.a & 11.0 & 2.0 &.. &.. \\
July 2000* & 58.8 & 43.0 & n.a. & 20.9 & 8.8 &.. &.. \\
January 2001* & 60.3 & 43.9 & 19.7 & 20.6 & 4.1 &.. &.. \\
July 2001* & 61.0 & 45.1 & 18.3 & 15.2 & 0.2 &.. &.. \\
January2002* & 61.3 & 45.7 & 19.7 & 15.4 & 0.7 &. &.. \\
July 2002* & 62.1 & 43.3 & 21.8 & 17.3 & 0.5 & 0.7 & 0.9 \\
January 2003* & 62.6 & 42.5 & 20.2 & 19.4 & 0.4 & 0.6 & 0.5 \\
July 2003 & 65.9 & 43.0 & 22.6 & 18.1 & 0.7 & 0.4 & 0.5 \\
\hline
\end{tabular}

Note: Multiple choices possible.

Source: CNNIC Survey 
Table 15.11 Time of usual online use (multiple choice) (per cent)

\begin{tabular}{lcccc}
\hline Time & $0-1 \mathrm{am}$ & $2-3 \mathrm{am}$ & $4-5 \mathrm{am}$ & $6-7 \mathrm{am}$ \\
July 2000 & 24 & 11.05 & 6.38 & 13.02 \\
January 2001 & 10.58 & 2.9 & 1.68 & 3.32 \\
July 2001 & 14.1 & 4.1 & 3.3 & 3.7 \\
January 2002 & 14.9 & 5.0 & 2.8 & 3.5 \\
July 2002 & 15.2 & 6.4 & 3.9 & 4.8 \\
& & & & \\
Time & $8-9 \mathrm{am}$ & $10-11 \mathrm{am}$ & $12-1 \mathrm{pm}$ & $2-3 \mathrm{pm}$ \\
July 2000 & 43.1 & 37.3 & 36.1 & \\
38.77 & & & & \\
January 2001 & 17.4 & 22.0 & 21.9 & 17.85 \\
July 2001 & 24.4 & 30.8 & 29.3 & 42.1 \\
January2002 & 16.9 & 21.2 & 22.7 & 33.6 \\
July 2002 & 20.4 & 21.2 & 26.4 & 34.9 \\
& & & & \\
Time & $4-5 \mathrm{pm}$ & $6-7 \mathrm{pm}$ & $8-9 \mathrm{pm}$ & $10-11 \mathrm{pm}$ \\
July 2000 & 32.94 & 42.96 & 75.57 & 62.56 \\
January 2001 & 28.49 & 33.56 & 62.47 & 35.12 \\
July 2001 & 35.9 & 39.5 & 77.2 & 49.8 \\
January 2002 & 29.7 & 40.0 & 77.0 & 45.4 \\
July 2002 & 33.6 & 48.5 & 80.5 & 46.5 \\
\hline
\end{tabular}

Source: CNNIC Survey

Table 15.12 Hardware used to go online (per cent)

\begin{tabular}{lccc}
\hline Year & $\begin{array}{c}\text { Desktop } \\
\text { computer }\end{array}$ & $\begin{array}{c}\text { Notebook } \\
\text { computer }\end{array}$ & $\begin{array}{c}\text { Others } \\
\text { (millions) }\end{array}$ \\
July 2002 & 97.4 & 4.5 & 1.29 \\
January 2003 & 95.2 & 10.1 & 1.53 \\
July 2003 & n.a. & n.a. & n.a. \\
\hline
\end{tabular}

Note: * Including mobile devices and info home appliances.

Source: CNNIC Survey 
Figure 15.2(a) Times users usually go online, January 2003 (per cent)

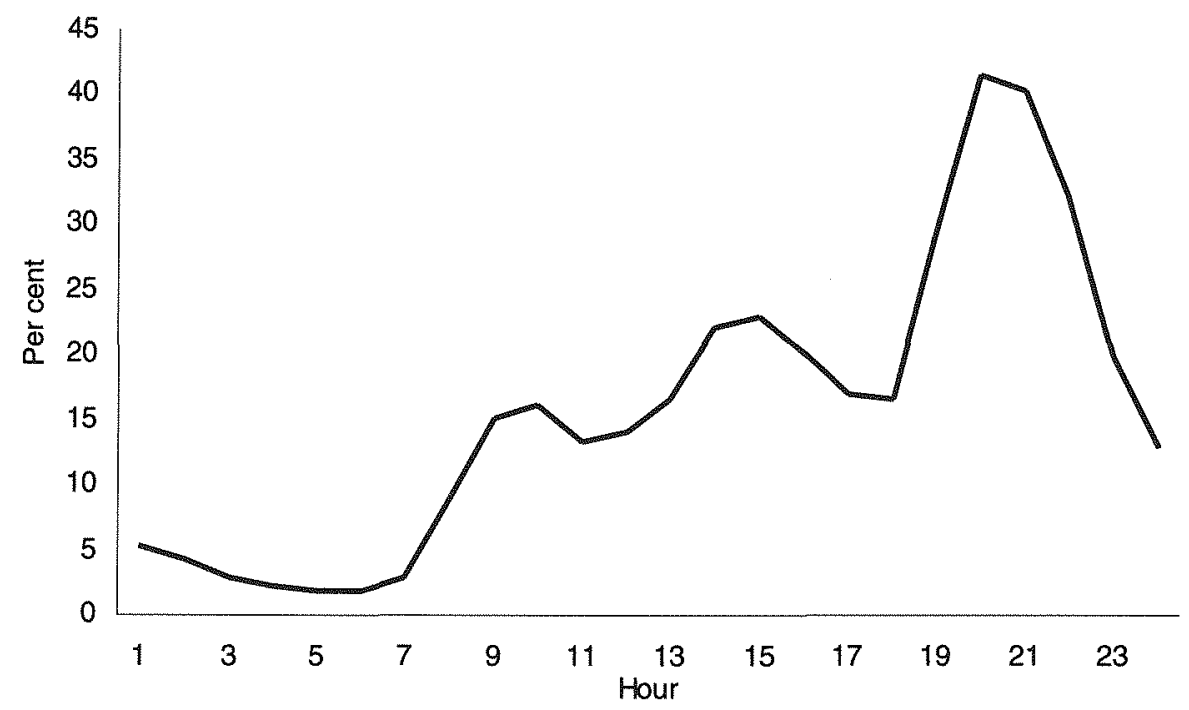

Figure 15.2(b) Times users usually go online, July 2003 (per cent)

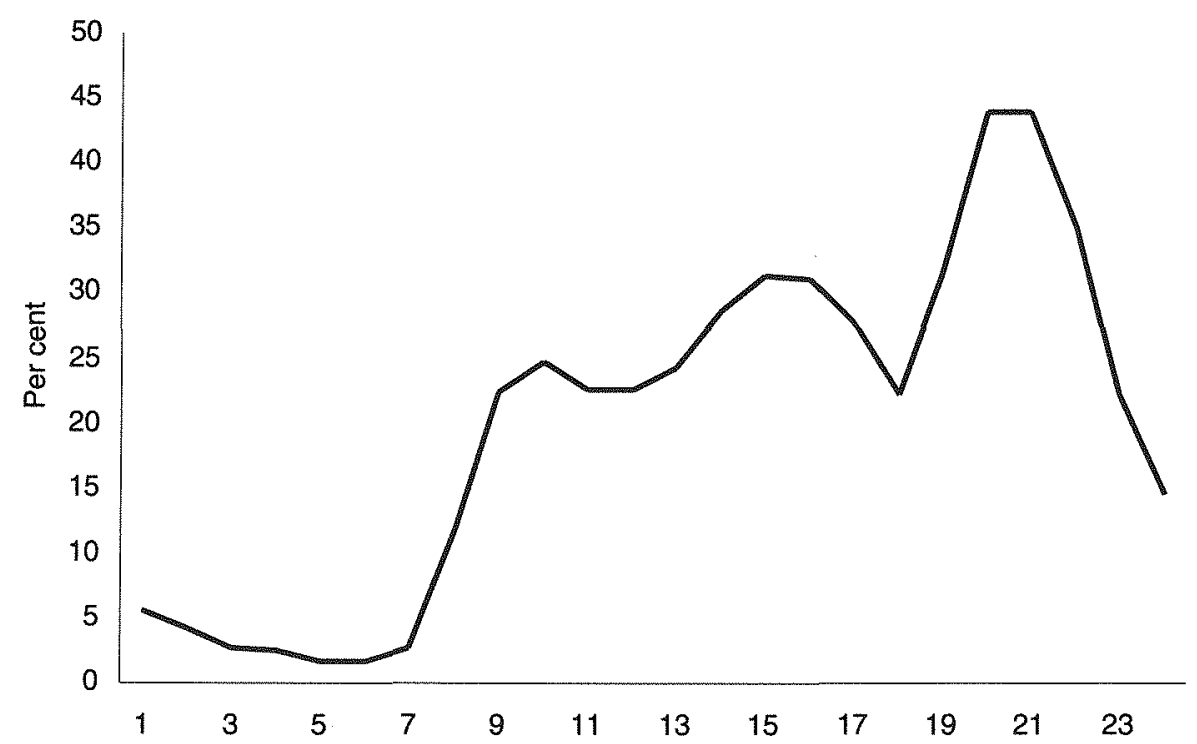


Table 15.13 Main purpose for going online (per cent)

\begin{tabular}{|c|c|c|c|c|c|c|}
\hline Year & Information & Study & Work & Leisure & $\begin{array}{c}\text { Emotional } \\
\text { needs }\end{array}$ & $\begin{array}{l}\text { Making } \\
\text { friends }\end{array}$ \\
\hline July 2001 & 42.9 & 4.3 & 5.8 & & $-34.4=$ & - \\
\hline January 2002 & 46.1 & 4.3 & 6.2 & - & $-31.1-$ & - \\
\hline July 2002 & 47.6 & 6.6 & 1.6 & 18.9 & 1.2 & 14.9 \\
\hline January 2003 & 53.1 & 4.8 & 2.0 & 24.6 & 1.1 & 7.0 \\
\hline July 2003 & 46.9 & 7.2 & 0.8 & 28.6 & 0.1 & 7.5 \\
\hline Year & $\begin{array}{c}\text { Obtain } \\
\text { free things* }\end{array}$ & $\begin{array}{l}\text { Commun- } \\
\text { ications }{ }^{\star \star}\end{array}$ & $\begin{array}{c}\text { Stock } \\
\text { trading }\end{array}$ & $\begin{array}{l}\text { Online } \\
\text { shopping }\end{array}$ & $\begin{array}{l}\text { Fashion, } \\
\text { curiosity }\end{array}$ & Others \\
\hline July 2001 & 3.1 & 4.1 & 4.1 & 0.3 & 0.5 & 0.5 \\
\hline January 2002 & 3.3 & 4.9 & 2.5 & 0.4 & 0.6 & 0.6 \\
\hline July 2002 & 1.2 & 4.4 & 0.9 & 0.3 & 0.3 & 2.1 \\
\hline January 2003 & 1.9 & 3.8 & 1.1 & 0.1 & 0.3 & 0.2 \\
\hline July 2003 & 1.7 & 3.2 & 2.1 & 0.2 & 06 & 1.1 \\
\hline
\end{tabular}

Notes: a Including free business activities abd academic research. ${ }^{b}$ Such as free email, personal homepage space, resources downloading, etc. ${ }^{c}$ Such as sending and receiving emails, short messages, faxes, etc.

Source: CNNIC Survey

Figure 15.3 Number of people using mobile devices and info home appliances to access internet

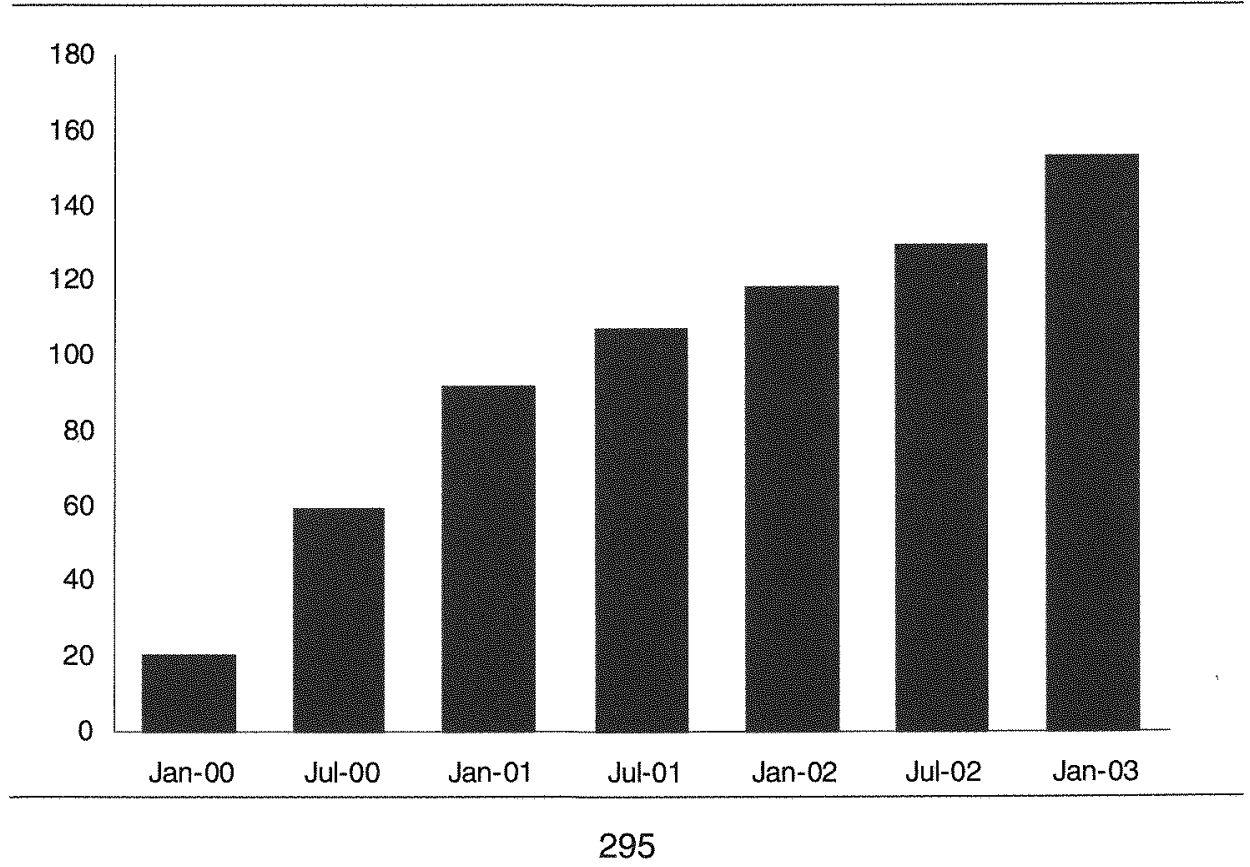


Language is obviously an issue in China, where most people do not speak any foreign language. It is thus not surprising to see that most people seek information, mostly domestic, in Chinese (see Table 15.14).

The overall picture of internet use in China indicates that business to consumer electronic commerce still has a long way to go, due to the youth and low incomes of most users. Nevertheless, it is still important to examine this aspect in more detail. Table 15.15 summarises people's view of online transaction problems. The internet

Table 15.14 Type of information users read online (per cent)

\begin{tabular}{|c|c|c|c|c|}
\hline & \multicolumn{2}{|c|}{$\begin{array}{l}\text { Information } \\
\text { in Chinese }\end{array}$} & \multicolumn{2}{|c|}{$\begin{array}{c}\text { Domestic } \\
\text { information }\end{array}$} \\
\hline January 2001 & \multicolumn{2}{|c|}{77.5} & \multicolumn{2}{|c|}{70.94} \\
\hline July 2001 & \multicolumn{2}{|c|}{78.7} & \multicolumn{2}{|c|}{71.3} \\
\hline January 2002 & \multicolumn{2}{|c|}{78.1} & \multicolumn{2}{|c|}{69.3} \\
\hline July 2002 & \multicolumn{2}{|c|}{81.4} & \multicolumn{2}{|c|}{71.4} \\
\hline \multirow[t]{2}{*}{ January 2003} & \multicolumn{2}{|c|}{81.3} & \multicolumn{2}{|c|}{71.1} \\
\hline & $\begin{array}{l}\text { Chinese info } \\
\text { mainland sites }\end{array}$ & $\begin{array}{l}\text { Chinese info } \\
\text { overseas site }\end{array}$ & $\begin{array}{l}\text { English info } \\
\text { mainland site }\end{array}$ & $\begin{array}{l}\text { English into } \\
\text { overseas site }\end{array}$ \\
\hline July 2003 & 80.9 & 7.7 & 5.0 & 5.8 \\
\hline
\end{tabular}

Source: CNNIC Survey

Table 15.15 User perception of important problems of online transactions (per cent)

\begin{tabular}{|c|c|c|c|c|c|c|c|}
\hline & Security & $\begin{array}{l}\text { Incon- } \\
\text { venience }\end{array}$ & $\begin{array}{l}\text { Product } \\
\text { quality }\end{array}$ & $\begin{array}{c}\text { Delivery } \\
\text { delay }\end{array}$ & $\begin{array}{l}\text { Price not } \\
\text { attractive } \\
\text { enough }\end{array}$ & $\begin{array}{l}\text { Online } \\
\text { into. not } \\
\text { reliable }\end{array}$ & $\begin{array}{l}\text { Other } \\
\text { factors }\end{array}$ \\
\hline July 1999 & 30.0 & 22.0 & 34.0 & 6.0 & 8.0 & n.a. & n.a \\
\hline January 2000 & 36.5 & 17.68 & 27.6 & 9.2 & 7.78 & n.a. & 1.1 \\
\hline July 2000 & 31.7 & 13.3 & 28.33 & 10.1 & 7.7 & 7.28 & 1.4 \\
\hline January 2001 & 31.2 & 12.59 & 32.0 & 9.8 & 7.39 & 5.9 & 1.0 \\
\hline July 2001 & 33.4 & 11.5 & 33.0 & 8.7 & 6.6 & 6.0 & 0.8 \\
\hline January 2002 & 31.0 & 11.8 & 30.2 & 13.9 & 6.3 & 6.3 & 0.5 \\
\hline July 2002 & 22.1 & 13.0 & 36.9 & 10.2 & 11.1 & 5.9 & 0.8 \\
\hline January 2003 & 23.4 & 10.8 & 39.3 & 8.6 & 10.8 & 6.4 & 0.7 \\
\hline July 2003 & 25.1 & 9.9 & 40.0 & 7.1 & 10.3 & 7.0 & 0.6 \\
\hline
\end{tabular}

Notes: 1 Product quality, after-sales service and merchant trustworthiness without guarantee. Source: CNNIC Survey 
security issue is universal so it is not surprising to see it in China. But people seem to worry less about this issue in recent years, and more (nearly 40 per cent) worry about quality control. This may be a result of fraud issues in the Chinese business environment. The credibility problem in the Chinese business world is so severe that this is more a business problem than a technological problem. Inconvenience of payment methods and unattractive pricing is also contributing to the online retailing stagnation.

A good sign of progress, if slow, is reflected in Table 15.16. Almost one third of Internet users had purchased goods or services online by January 2003. During the period of SARS in China, even more people (as reflected by the clear growth in the July 2003 survey) have switched to online shopping and found it satisfactory, to their surprise. Newspapers had reported people saying that they would not want to go to the crowded shopping malls after they had experienced pleasant shopping processes online, even for big-ticket items such as refrigerators. Ironically, the outbreak of SARS has given a good push for e-commerce development in China. The change of shopping habits will have a profound impact in China's retailing, although it may take some time.

The variety of goods and services purchased online is summarised in Table 15.17. One can see that books, music products and computer-related products are the major items, although computer-related products are declining. It is natural to search for computer-related products online, since online users will be more familiar with computers. The other two categories are small-ticket items, occupying a small portion of their respective markets. Internet market for consumer goods in China is still far behind other regions such as the United States and South Korea.

Table 15.16 Goods or services purchased online (per cent)

\begin{tabular}{lcc}
\hline & Yes & No \\
January 2000 & 8.8 & 91.2 \\
July 2000 & 16.3 & 83.7 \\
January 2001 & 31.7 & 68.3 \\
July 2001 & 31.9 & 68.1 \\
January 2002 & 31.6 & 68.4 \\
July 2002 & 31.2 & 68.8 \\
January 2003 & 33.8 & 66.2 \\
July 2003 & 40.7 & 59.3 \\
\hline
\end{tabular}

Source: CNNIC Survey 
Table 15.17 Proportion of users who purchased (multiple choice) (per cent)

\begin{tabular}{|c|c|c|c|c|c|c|}
\hline Year & $\begin{array}{l}\text { Books and } \\
\text { Magazines }\end{array}$ & $\begin{array}{l}\text { Computer } \\
\& \text { related }\end{array}$ & $\begin{array}{l}\text { Camera } \\
\& \text { related }\end{array}$ & $\begin{array}{l}\text { Telecom } \\
\text { \& related }\end{array}$ & $\begin{array}{l}\text { Music, } \\
\text { image, etc. e }\end{array}$ & $\begin{array}{l}\text { Home } \\
\text { electronics }\end{array}$ \\
\hline July 2000 & 45.1 & 37.2 & 7.5 & 17.1 & 15.6 & 9.4 \\
\hline January 2001 & 58.3 & 37.5 & 4.9 & 19.9 & 29.1 & 8.4 \\
\hline July 2001 & 58.7 & 35.5 & 4.8 & 18.0 & 29.5 & 7.4 \\
\hline January 2002 & 58.0 & 33.7 & 3.6 & 15.5 & 34.4 & 5.6 \\
\hline July 2002 & 69.0 & 33.2 & 4.3 & 11.6 & 38.3 & 7.3 \\
\hline January 2003 & 67.7 & 29.9 & 6.2 & 12.5 & 34.9 & 7.1 \\
\hline \multirow[t]{2}{*}{ July $2003^{*}$} & 63.8 & 30.7 & 7.7 & 12.5 & 31.4 & 8.0 \\
\hline & Clothing & $\begin{array}{l}\text { Sport } \\
\text { items }\end{array}$ & $\begin{array}{l}\text { Living, } \\
\text { residence \& } \\
\text { services }\end{array}$ & $\begin{array}{l}\text { Medical, } \\
\text { health \& } \\
\text { services }\end{array}$ & $\begin{array}{l}\text { Gifts \& } \\
\text { services }\end{array}$ & \\
\hline July 2000 & 7.68 & 6.96 & 12.11 & 4.91 & 11.23 & \\
\hline January 2001 & 6.92 & 6.91 & 14.29 & 4.44 & 16.41 & \\
\hline July 2001 & 5.9 & 6.1 & 11.8 & 3.8 & 13.8 & \\
\hline January 2002 & 4.4 & 4.4 & 11.6 & 3.1 & 14.7 & \\
\hline July 2002 & 5.0 & 5.4 & 11.6 & 3.0 & 12,1 & \\
\hline January 2003 & 5.5 & 4.7 & 11.0 & 2.7 & 12.7 & \\
\hline \multirow[t]{2}{*}{ July $2003^{*}$} & 7.8 & 5.4 & 13.5 & 3.7 & 11.8 & \\
\hline & $\begin{array}{l}\text { Financial, } \\
\text { insurance }\end{array}$ & $\begin{array}{l}\text { Education } \\
\text { \& study } \\
\text { services }\end{array}$ & $\begin{array}{l}\text { Ticketing } r \\
\text { services }\end{array}$ & $\begin{array}{l}\text { Hotel } \\
\text { reservation } \\
\text { service }\end{array}$ & Others & \\
\hline July 2000 & 4.64 & 10.15 & 9.62 & n.a. & 11.13 & \\
\hline January 2001 & 3.76 & 13.13 & 8.45 & n.a. & 9.04 & \\
\hline July 2001 & 3.3 & 12.9 & 8.3 & n.a. & 4.1 & \\
\hline Jan. 2002 & 2.6 & 11.8 & 9.7 & n.a. & 3.1 & \\
\hline July 2002 & 2.5 & 9.5 & 7.9 & 5.2 & 1.8 & \\
\hline January 2003 & 2.1 & 9.8 & 7.7 & 4.3 & 2.3 & \\
\hline July $2003^{*}$ & 2.3 & 9.6 & $4.6^{*}$ & 3.8 & 2.0 & \\
\hline
\end{tabular}

Note: * SARS period.

Source: CNNIC Survey

Tang and Liu (2003) have a detailed case study of the online book market in China, the results of which will not be repeated here. Briefly, even the most developed part of the online markets in China (books) is immature.

\section{THE IMPACT OF THE INTERNET ON CHINESE MARKETS}

Internet development in China started far behind other countries and progressed slowly in the early years, mainly due to the political hurdles imposed by the United 
States. From mid 1990s however, it has started to fly, even during the period when the internet bubble burst in the financial markets in other regions of the world.

However, people in China still mainly use Internet for information and leisure activities, rather than for business or governmental activities. Business-to-business electronic commerce in China is far behind other regions, not only because of technological problems, but also because of management and social culture issues.

Ironically, the outbreak of SARS has pushed e-commerce and Internet development in China, since overseas visitors were unwilling to come so an alternative approach had to be in place for orders and transactions. The Chinese government has been very supportive of internet development and heavily financed e-government programs. From this perspective, the market potential in this vast country is enormous, although it would only show up in the medium to long run. The profound impact of Internet development will gradually, and in some cases dramatically, be felt in Chinese society, on its social system, culture and human relationships.

\section{ACKNOWLEDGMENTS}

The work described in this paper was fully supported by a grant from the Research Grants Council of the Hong Kong Special Administrative Region, China (Project No. CUHK4310/02H).

\section{NOTES}

1 According to the authoritative surveys by China Internet Network Information Center (CNNIC), www.cnnic.org.cn.

2 Details in the 12 survey reports are available on www.cnnic.org.cn.

3 Online users number about 655 million globally by the end of 2002, according to the report from the UN Trade and Development Conference.

\section{REFERENCES}

Tang, F-F., 2002. 'What is behind the exceptionally successful broadband market in South Korea?', Web Journal of Chinese Management Review, 5(2):n.p.

Tang, F-F. and Liu, Y., 2003. Development of Online Pricing Efficiency: empirical results from China's book market, Working Paper, Chinese University of Hong Kong, Hong Kong. 